ISSN 1112-9867

\title{
POST-MATCH RECALL OF SERVE AND SERVE-RETURN PATTERNS IN HIGH-PERFORMANCE JUNIOR MALE AND FEMALE TENNIS PLAYERS
}

\author{
H. Hizan ${ }^{1,3,}{ }^{*}$, P. Whipp ${ }^{2}$ and M. Reid ${ }^{3}$ \\ ${ }^{1}$ University of Western Australia, Perth, Australia \\ ${ }^{2}$ Tennis Australia, Private Bag 6060, Richmond South, 3121, Victoria, Australia \\ ${ }^{3}$ Faculty of Sports Science and Coaching, Sultan Idris Education University, Perak, Malaysia
}

Published online: 10 November 2017

\begin{abstract}
This study examined the capability of high-performance junior tennis players to recall spatial distribution of the serve and serve-returns during a national tennis competition. The subjects in two age categories namely under $12(n=13)$ and under $16(n=19)$ were tested on recall memory of their performance. There is no gender or age group differences existin the players' capacity to detect and document their own and their opponent's service and serve-return patterns. Mann-Whitney U test showed that the players had comparably developed declarative knowledge bases. The use of more objective notational, game reviews or instructional tools, particularly for players within this age group. Junior players are encouraged to improve and reshape the core aspects of cognitive processing such as memory, attention and sensory processing, through interactive multimedia software technology and self-organized learning environments.
\end{abstract}

Keywords: serve-return; memory recall; knowledge base.

Author Correspondence, e-mail: hazhizan1@gmail.com

doi: http://dx.doi.org/10.4314/jfas.v9i6s.36 


\section{INTRODUCTION}

The knowledge base of an athlete is the foundation by which the athlete operates during competition. In the first instance, an athlete accesses his knowledge base in preparation for executing a particular action under specific conditions. Then, he acts and receives feedback from his actionsand if required, this feedback is used to refine this knowledge base that he applied. Such interaction occurs at many levels, resulting in the continuous cycling of an athlete's response selection (i.e., declarative knowledge-'what to do') and their response execution (i.e., procedural knowledge-'doing it'). Similarly, this process is also used in the subsequent updating of the athlete's knowledge base. Thus, in an effort to better understand tactical subtleties that comprise sports expertise,a player needs to initially evaluatehisknowledge base [1].

The expression knowledge base is commonly used to describe the interactions of working memory and long-term memory [2]. Several memory models denote working memory as part of long-term memory [3-4]. The recall of sport declarative knowledge (response selection) is generally believed to be linked to working memory processes (working memory and/or long-term memory). Deficiencies in players' performance or more specifically in their response selection and response execution, can result from errors in working memory, insufficient information in long-term memory and ineffective processes for storing and retrieving information from long-term memory [5-7]. As posited by the long-term working memory theory, sufficient psychological learning, skills and resources are needed in order to recall events before undergoing retrieval. Shortages in player's ability to recall and retrieve sports information could be a result of a lapse in the memory because the player's brain was only able to increase chemical signalling between the neurons, and did not induce the structural changes that are necessary to support long-term memory [8].

Past studies in tennis looked into the assessment of response selection, which often manifests as declarative knowledge. In here, they generally focused on the recall of isolated shots and actions, often using edited film clip simulations [9-11]. More recently, plasma touch screens have been utilized to study participant's speed of response to situational probability information in the return of serve game situation [12]. In relation, the presentation of actual match scenarios 
and verbal protocol analyses (interviews) represent other common procedures of assessing a player's declarative knowledge [13-18, 11].

The ecological validity of some of these approaches, however, can be of concern [19-20]. For instance, it is more difficult to read the spatiotemporal information of the path of incoming balls from video than in actual game scenarios [19]. Such methods often lead to overestimation of ball flight and are devoid of the context present during match play. Other researchers argue that the duration of these clips are frequently too short to even present the contextual cues that relate to the previous sequences of shots that may have affected the participant's predictions and expectations [21]. In relation, players' perceptual processes were more heavily involved in match play than in practice when the motor and perception skills of high-performance table-tennis players were examined during practice and actual tournament play [22]. Accordingly, this could have been largely due to thegreater inherent unpredictability of gameplay.

During competitions, athletes scan, read, recognise, recall and process competition information concurrently along with other pieces of information such as environmental conditions and how to overcome/beat an opponent. For example, when returning a service in tennis, the returner needs to take into account several characteristics about the serve (e.g., the serve landing location, spin and speed of the serve) as well as their own serve-return response execution (i.e., technical aspects). The player will do this while also deciding on the best location to hit their serve-return to increase the probability of winning the point-and all of this happens in less than a second. Evidence also points to elite players adopting different strategies (and potentially thought processes) when considering level, leading and trailing on service breaks [23-24]. Given the complex interactions that characterise and appear unique to game-play, only a few have done a parallel observation or video analysis of actual competition in order to establish a more valid and systematic approach for evaluating declarative and procedural knowledge of high-performance players [25]. Much of the existing work of this nature in tennis focused on questioning the players before or after a point in practice match settings [11, 13, 15, 17-18]. Findings for the most part suggest that adult experts are more advanced in their tactical knowledge than youth experts or novices (irrespective of age) as evidenced by the adults' more elaborate action plans and current event profiles.However, one significant limitation of this 
approach is the fact that they are usually seen during match plays in practice settings. With the idea that actual competition is 'different' to practice [24], it is surprising that lack of such analysis is seen in literature, particularly on evaluating a player's declarative knowledge via recognition and recall in an actual game context [1].

In this current study, we focused on the recall memory of players via post-match questionnaires to minimise the disruption of the continuous nature of tennis play [1] and to address some of the gaps in the above-mentioned studies. In essence, this study examined the capability of high-performance junior tennis players to recall patterns of play in relation to the serve and serve-returns hit during a national tennis tournament. This study provides an insight into whether junior players are sensitive to, and therefore able to recall, the spatial distribution of the first two shots in tennis at different stages throughout the match. This body of work is able to extend our understanding of the knowledge base of junior players, which in turn could assist coaches to emphasise on the tactical development of their players.

\section{METHODOLOGY}

\subsection{Participants}

The study sample is comprised of high-performance junior tennis players categorisedinto two groups namelyunder 12 players $(n=13)$ and under $16(n=19)$, competing at the 2008 Australian National Junior Singles Championships. The average age of the players in the sample is 13.4 years $(\mathrm{SD}=2.04)$. The detailed breakdown of the participants' profile (including the number of matches played, mean age, standard deviation, total number serve and serve-returnanalysed) are presented in Table 1. Before the data gathering, it was ensured that all participants understood and signed the Informed Consent for Human Participant in accordance with the ethics regulations of the University of Western Australia.

Table 1. Characteristics of the participants in the study

\begin{tabular}{ccccccc}
\hline Group & Male (n) & Female (n) & Mean Age & SD & Serves Total & Returns Total \\
\hline Under-12 & 6 & 7 & 11.0 & 0.3 & 1295 of 1436 & 1128 of 1312 \\
Under-16 & 10 & 9 & 15.1 & 0.4 & 2184 of 2843 & 1839 of 2145 \\
\hline
\end{tabular}

\subsection{Instrument}

The capacity of the players to recognize their own and their opponent's serve and serve-return 
patterns was assessed using a 40-item post-match questionnaire. The questionnaire was separated into ten categories relating to different aspects of serve and serve-return performance, each represented by four questions (see Table 2 for a sample question from each category).

Responses to items related to the serve location are designated on both sides of the court by 3 values: $1, \mathrm{~W}$ - Wide or serves that are going away from the returner across the tramlines; 2 , B - Body or serves into the returner's body and 3, T - serves near the center service line. Responses to items related to the serve-return location are designated by 6 values (i.e., 3 values representing 3 deep return locations and 3 values representing 3 short return locations).

Table 2.Example of category of pattern recognition questionnaire in tennis

\section{Category of Pattern Recognition}

1. Recognising Own Serve Location(independent of score) (ROWS) (Questions number: 1, $3,5,7)$ Sample question - "Where did you hit most of your first serves (that landed in, i.e., not faults) on the deuce side?"

2. Recognising Own Serve Location (dependent of score) (ROWSWS) (Questions number: $9,11,13,15)$ Sample question - "During the match, if you served at 15-40, where did you hit most of your first serve in?"

3. Recognising Own Serve-return Location (independent of score) (ROWR) (Questions number: 37, 38, 39, 40) Sample question - "Where did you hit your first serve-returns most of the time on the deuce side?"

4. Recognising Own Serve-return Based on Where Opponent had served (independent of score) (ROSRBOS) (Questions number: 18, 20, 22, 24) Sample question -"When your opponent hit first serves to the location you have identified in question (17), where did you return most of the time?"

5. Recognising Own Serve-return Based on Where Opponent had served (dependent of score) (ROSRBOSS) (Questions number: 26, 28, 30, 32)

Sample question - "When your opponent hit first serves to the location you have identified in question (25), where did you return most of the time?"

6. Recognising Opponent Serve Location (independent of score)(ROPSLNS) (Questions 
number: 17, 19, 21, 23) Sample question - "Where did your opponent hit most of his/her first serves (that landed in, i.e., not faults) on the deuce side?"

7. Recognising Opponent Serve Location (dependent of score) (ROPSLWS) (Questions number: 25, 27, 29, 31) Sample question - "During the match, if your opponent served at 15-40, where did he/she hit most of his/her first serves (that landed in)?"

8. Recognising Opponent Serve-return (independent of score)(RORSNS) (Questions number: 33, 34, 35, 36) Sample question - "Where did your opponent hit his/her first serve-return most of the time on the deuce side?"

9. Recognising Opponent Serve-return Based on Where You had served (independent of score) (ROSRBYSNS) (Questions number: 2, 4, 6, 8) Sample question - "When hitting first serves to the location you have identified in question (1), where did your opponent return most of the time?"

10. Recognising Opponent Serve-return Based on Where You had served (dependent of score) (ROSRBYSWS) (Questions number: 10, 12, 14, 16) Sample question - "When hitting first serves to the location you have identified in question (9), where did your opponent return most of the time?"

\subsection{Procedures}

Permission to analyze the matches from the 2008 Optus Under-12 and Under-16 Australian Boys and Girls Tennis Singles Championships in Melbourne was obtained from Tennis Australia. Moreover, written permission to interview the players post-match was obtained from the players, their parents and coaches prior to competing in the tournament. All parties were briefed as to the nature of the study and the involvement of the players, which also includes the right of the players to withdraw from the study at any time. Upon completion of their match, the participants completed the Pattern Recognition Questionnaire in relation to the recently completed match. The participants accomplished the questionnaire 15-20 minutes after the match in a private room under the supervision of the researchers. Players were also instructed to leave the item(s) blank if they could not confidently recall the circumstances (i.e., they were encouraged not to guess). Coaches were requested to refrain from assisting the players with the questionnaire. The average time taken to complete the questionnaire was 25 minutes. 


\subsection{Data Recording}

All tennis matches were recorded using a SONY digital video camera (25 frames/seconds). After the recording of the matches, the images were converted from MPEG file to AVI using Pinnacle Studio 12 to allow for further coding of the activity. The matches and ball trajectories from round 16 onward were recorded from fixed position approximately 8 meters high and 6 meters behind the baseline. The camera was placed and adjusted so that the doubles alleys could be seen. The coder watched the video and manually codedevery point in these matches so that the location of the serve and serve-return executed by each player are cross-tabulated.

The following audio-visual equipment were used: (1) Sony digital video camera recorder (model DCR-SR42E) (40xOptical Zoom) (hard disk drive-30GB), (2) Sony wide-angle conversion lens (VCL-0630X 30mm 0.6X) and (3) Camera mount (video camera support for tennis court fence) which was designed by the Sport Science Department at the University of Western Australia. This camera mount consisted of a bottom support bracket manufactured from aflat bar $(32 \times 6 \mathrm{~mm})$ and a $6 \mathrm{~mm}$ round bar, bent in a hook and was located above the fence. The inside diameter is $57 \mathrm{~mm}$. A $16 \mathrm{~mm}$ bar with threads at the top of the bar supported a tripod universal joint. The main support bar is $350 \mathrm{~mm}$ long and the main bracket bar is 200x130mm.

\subsection{Criteria for Determining Correctness}

Codes were used to denote the correctnessof a player's response: $0=$ incorrect answer and $1=$ correct answer. The code $\mathrm{X}=$ question was used for the questions excluded from the analysis because of insufficient observations. 
Table 3. Application of criteria for determining correctness and incorrectness of pattern recognition and deletion of question from analysis

Cross-Tabulation Result for 3 Locations (Serves)

\begin{tabular}{|c|c|c|c|c|c|c|c|}
\hline Case \# & Location 1 & Location 2 & Location 3 & \multicolumn{4}{|c|}{ Decision for Correctness } \\
\hline 1 & 1 & 1 & 1 & \multicolumn{4}{|c|}{ Excluded } \\
\hline 2 & 2 & 2 & 2 & \multicolumn{4}{|c|}{ Correct for Location $1,2,3$} \\
\hline 3 & 1 & 1 & 0 & \multicolumn{4}{|c|}{ Excluded } \\
\hline 4 & 2 & 0 & 2 & \multicolumn{4}{|c|}{ Correct for location 1 and 3} \\
\hline 5 & 3 & 3 & 0 & \multicolumn{4}{|c|}{ Correct for location 1 and 2} \\
\hline 6 & 2 & 1 & 0 & \multicolumn{4}{|c|}{ Correct for location 1} \\
\hline 7 & 0 & 0 & 0 & \multicolumn{4}{|c|}{ If players leave blank, correct answer was given } \\
\hline \multicolumn{8}{|c|}{ Cross-Tabulation Result for 6 Locations (Serve-Returns) } \\
\hline \multirow[t]{2}{*}{ Case \# } & Location 1 & Location & Location & Location & Location & Location & Decision for \\
\hline & & 2 & 3 & 4 & 5 & 6 & Correctness \\
\hline \multirow{3}{*}{8} & \multirow{3}{*}{2} & \multirow{3}{*}{2} & \multirow{3}{*}{0} & \multirow{3}{*}{0} & \multirow{3}{*}{0} & \multirow{3}{*}{0} & Correct for \\
\hline & & & & & & & location 1 and \\
\hline & & & & & & & 2 \\
\hline \multirow{2}{*}{9} & \multirow{2}{*}{0} & \multirow{2}{*}{1} & \multirow{2}{*}{2} & \multirow{2}{*}{0} & \multirow{2}{*}{0} & \multirow{2}{*}{0} & Correct for \\
\hline & & & & & & & location 3 \\
\hline 10 & 1 & 1 & 0 & 0 & 1 & 0 & Excluded \\
\hline 11 & 1 & 1 & 1 & 0 & 1 & 0 & Excluded \\
\hline
\end{tabular}

All questionnaire items were included in the analysis. For cross-tabulation, the frequency of responses required for that question to be included needed to be $\geq 3$. Table 3 elaborates on how the various criteria for determining thecorrectness of a player's response (and detection of serve and serve-return patterns) as well as the exclusion of specific questions were applied. The explanation on the decision made for each case was given separately.

1. Case 1: The question is excluded from further analysis because the instances of the serve landing in the 3 parts of the service box totalled 3 and were evenly distributed. 
2. Case 2: The question is included for analysis because the instances of the serve landing in the 3 parts of the service box totalled 6 and were evenly distributed.

3. Case 3: The question is excluded from further analysis because only 2 instances of the serve landing in the 3 parts of the service box were correct, totalling 2; the minimum total of 3 correct instances had not been met.

4. Case 4: The question is included for analysis because the instances of the serve landing in 2 parts of the service box totalled 4; thus, the players selected location 1 or location 3 correctly.

5. Case 5: The question is included for analysis because the instances of the serve landing in 2 parts of the service box totalled 6; thus, the players selected location 1 or location 2 correctly.

6. Case number 6: The question was included for analysis because minimum response requirement $(\geq 3)$ was met; the serve landing location has the most number of instances; thus, location 1 is considered the correct serve location.

7. Case 7: If the actual count was zero and the players left the 3 serve landing locations blank, the question was included for analysis because this was correct. If a player had selected location 3 , but there were actually zero instances in the match, then the response would be deemed incorrect.

8. Case 8: The question was included for analysis because the instances of the serve-return landing location in the 6 parts of the court totalled 4, exceeding the minimum response required $(\geq 3)$; the response was correct for location 1 and location 2, an even 2-2 total number of instances split.

9. Case 9: The question was included for analysis because minimum response requirement $(\geq$ 3) was met; the serve-return location 3 has the most number of instances; thus, location 3 is considered the correct serve-return location.

10. Case 10: This question was excluded from the analysis because although it met the $\geq 3$ criteria for instances, no one cell recorded the highest number of instances.

11. Case 11: This question was excluded from the analysis because although it met the $\geq 3$ criteria for instances, no one cell recorded the highest number of instances. 


\subsection{Statistical Analyses}

The distributions of the serve and serve-return locations were calculated using cross-tabulation. These shot distributions were summarized according to the demarcation of the court designed for serve and serve-returns (serve landing locations: wide, body and $\mathrm{T}$ locations separately on the deuce and advantage sides of the court and return landing locations, i.e., sections 1, 2, 3 represent deep returns and sections 4,5 and 6 represent short returns). Cross-tabulation was also done for the 10 categories to produce a count and total count of every player's serve and serve-return locations.

The player's recalling abilities were compared with the coded distribution of these same shots from the same match. This was performed to determine a player's accuracy in recognising and recalling their own and their opponent's serve and serve-return patterns on both sides of the court. In this context, high scores reflect agreater accuracy of a player's recall. Mann-Whitney $\mathrm{U}$ test was conducted to examine gender and age differences on ability to recognise and recall their own and their opponent's serve and serve-return patterns. An alpha level of .05 was utilised for all statistical tests.

\section{RESULTS AND DISCUSSION}

\subsection{Pattern Recognition Scores by Age Group and Gender}

Table 4 presents the scores for pattern recognition of serve and serve-return of junior tennis players according to age group and gender. The cross-tabulation shows that the range of median scores for both the under-12 and under-16 age groups in relation to their genderwere large (Under-12s, boys range from 5.6 to 50.0 and girls range from 16.7 to 75.0 ; Under-16s, boys range from 22.5 to 66.7 and girls range from 14.8 to 50.0 ). This suggests that the capacity for recall on the questionnaire items varied greatly among the players. 
Table 4.Descriptive statistics of pattern recognition scores by age group and gender

Under-12

Under-16

$\begin{array}{llll}\text { Boys } & \text { Girls } & \text { Boys } & \text { Girls }\end{array}$

\begin{tabular}{ccccccccc} 
Category & Median & Range & Median & Range & Median & Range & Median & Range \\
\hline C1.1 & 50.0 & $0-100$ & 50.0 & $0-75$ & 50.0 & $25-100$ & 50.0 & $25-75$ \\
C1.2 & 41.7 & $0-100$ & 0.0 & $0-66.7$ & 16.7 & $0-100$ & 16.7 & $0-100$ \\
C1.3 & 16.7 & $0-75$ & 50.0 & $0-75$ & 25.0 & $0-50$ & 25.0 & $0-75$ \\
C1.4 & 0.0 & $0-100$ & 50.0 & $0-100$ & 33.3 & $0-100$ & 50.0 & $0-100$ \\
C1.5 & 0.0 & $0-0$ & 100.0 & $0-100$ & 100.0 & $0-100$ & 50.0 & $0-100$ \\
C1.6 & 37.5 & $0-75$ & 50.0 & $25-100$ & 62.5 & $0-100$ & 50.0 & $0-100$ \\
C1.7 & 0.0 & $0-33.3$ & 16.7 & $0-100$ & 16.7 & $0-100$ & 0.0 & $0-50$ \\
C1.8 & 25.0 & $0-75$ & 25.0 & $0-50$ & 12.5 & $0-75$ & 25.0 & $0-100$ \\
C1.9 & 0.0 & $0-66.7$ & 25.0 & $0-100$ & 0.0 & $0-100$ & 0.0 & $0-100$ \\
C1.10 & 0.0 & $0-100$ & 50.0 & $0-100$ & 50.0 & $0-100$ & 0.0 & $0-0$ \\
\hline
\end{tabular}

Table 5 reports the pattern recognition accuracy percentages for the 10 categories. Category C1.1 relates to a player's level of accuracy in recalling their own serve locationindependent of the score. In this category, the under- 16 girls were accurate $100 \%$ of the time but the under-16 boys and under- 12 girls were equally accurate at $66.7 \%$ and the under- 12 boys were able to recall their serve position half of the time. When the players were asked to recall their own serve location behaviour as it related to a particular score (Category C1.2), all players were less accurate (Under-12 boys: 41.7\%, Under-16 boys and Under-16 girls: 16.7\%). The under-12 girls were in fact unable to recall their own serve locations when related to their score.

Category $\mathrm{C} 1.3$ relates to the players' capacities to accurately recall their own serve-return location regardless of the score. In here, only the under-12 girls demonstrated better than $50 \%$ response accuracy while the under-12 boys got the lowest percentage (22.3\%). When asked to recall their own serve-return based on where their opponent had served independent of thescore (Category C1.4), only the two subgroups for girls recorded a 50\% accuracy. The Under-12 boys were unable to recall their own serve-return location behaviour based on where their opponent had served. Category C1.5 assessed the player's recall accuracy about 
their own serve-return location based on where their opponent had served as it related to a particular score. In this case, the under-12 girls and the under-16 boys were $100 \%$ accurate while the Under-16 girls were only $50 \%$ accurate.

Table 5. The under-12 and under-16 pattern recognition accuracy percentages for the 10 categories

\begin{tabular}{|c|c|c|c|c|c|}
\hline \multirow{3}{*}{ Category } & \multirow{3}{*}{ Content } & \multicolumn{4}{|c|}{ Accuracy level (\%) } \\
\hline & & U12 & U12 & U16 & U16 \\
\hline & & Boys & Girls & Boys & Girls \\
\hline $\mathrm{C} 1.1$ & $\begin{array}{l}\text { Recalling Own Serve } \\
\text { Location(independent of score) }\end{array}$ & 50 & 66.7 & 66.7 & 100 \\
\hline $\mathrm{C} 1.2$ & $\begin{array}{l}\text { Recalling Own Serve Location } \\
\text { (dependent of score) }\end{array}$ & 41.7 & 0 & 16.7 & 16.7 \\
\hline $\mathrm{C} 1.3$ & $\begin{array}{l}\text { Recalling Own Serve-return Location } \\
\text { (independent of score) }\end{array}$ & 22.3 & 66.7 & 50 & 33.3 \\
\hline \multirow[t]{2}{*}{$\mathrm{C} 1.4$} & Recalling Own Serve-return Based on & & & & \\
\hline & $\begin{array}{c}\text { Where Opponent had served } \\
\text { (independent of score) }\end{array}$ & 0 & 50 & 33.3 & 50 \\
\hline \multirow[t]{2}{*}{$\mathrm{C} 1.5$} & Recalling Own Serve-return Based on & & & & \\
\hline & $\begin{array}{l}\text { Where Opponent had served } \\
\text { (dependent of score) }\end{array}$ & $\mathrm{n} / \mathrm{a}$ & 100 & 100 & 50 \\
\hline $\mathrm{C} 1.6$ & $\begin{array}{l}\text { Recalling Opponent Serve Location } \\
\text { (independent of score) }\end{array}$ & 50 & 66.7 & 62.5 & 50 \\
\hline $\mathrm{C} 1.7$ & $\begin{array}{l}\text { Recalling Opponent Serve Location } \\
\text { (dependent of score) }\end{array}$ & 0 & 16.7 & 16.7 & 0 \\
\hline $\mathrm{C} 1.8$ & $\begin{array}{l}\text { Recalling Opponent Serve-return } \\
\text { (independent of score) }\end{array}$ & 33.3 & 50 & 16.6 & 25 \\
\hline \multirow[t]{2}{*}{ C1.9 } & Recalling Opponent Serve-return & & & & \\
\hline & $\begin{array}{l}\text { Based on Where You had served } \\
\text { (independent of score) }\end{array}$ & 0 & 25 & 0 & 0 \\
\hline
\end{tabular}


C1.10 Recalling Opponent Serve-return

Based on Where You had served

0

50

50

$\mathrm{n} / \mathrm{a}$

(dependent of score)

When asked to recall their opponent's serve location not related to a particular score (Category C1.6), all player groups recorded 50\% accuracy or more with the under-12 girls topping the list with $66.7 \%$. Category $\mathrm{C} 1.7$ relates to being able to accurately recall their opponent's serve location as it related to a particular score. In this context, it is observed that the player subgroups had particularly poor recall accuracy.Only the under-12 girls and under-16 boys reported $16.7 \%$ accuracy in their responses. When asked to recall their opponent's serve-return location not related to a score (Category $\mathrm{C} 1.8$ ), only the under-12 girls were $50 \%$ accurate.

Category C1.9 assessed the player's accuracy in recalling their opponent's serve-return location based on where they themselves had served. The result shows that the under-12 girls were the only subgroup to accurately recall these locations, but only at $25 \%$ of the time. Finally, category $\mathrm{C} 1.10$ asked the players to recall their opponent's serve-return location based on where they themselves had served as it related to a particular score. Only the under-12 girls and under-16 boys were able to recall these locationswith $50 \%$ response accuracy.

\subsection{Difference in Pattern Recognition between the Under-12 Boys and Girls and the Under-16 Boys and Girls}

Tables 6 and 7 present the summary statistics of the Mann-Whitney $U$ tests for determining any age or gender effects on serve and serve-return pattern recognition. Only 8 of the 10 categories could be analyzed as there were insufficient data of observations for C1.5 and C1.10. 
Table 6. Summary statistics of the Mann-Whitney u tests: Difference in pattern recognition between the boys and girls from the under-12 and under-16 player groups

\begin{tabular}{|c|c|c|c|c|c|c|c|c|}
\hline \multirow{3}{*}{ Category } & \multicolumn{4}{|c|}{ Under-12 } & \multicolumn{4}{|c|}{ Under-16 } \\
\hline & \multicolumn{2}{|c|}{ Median } & \multirow{2}{*}{$\mathbf{U}$} & \multirow{2}{*}{$\mathbf{P}$} & \multicolumn{2}{|c|}{ Median } & \multirow{2}{*}{$\mathbf{U}$} & \multirow{2}{*}{$\mathbf{p}$} \\
\hline & Boys & Girls & & & Boys & Girls & & \\
\hline $\mathrm{C} 1.1$ & 50.0 & 50.0 & -0.367 & 0.731 & 50.0 & 50.0 & -0.215 & 0.842 \\
\hline $\mathrm{C} 1.2$ & 41.7 & 0.0 & -1.094 & 0.366 & 16.7 & 16.7 & -0.048 & 0.965 \\
\hline $\mathrm{C} 1.3$ & 16.7 & 50.0 & -0.673 & 0.534 & 25.0 & 25.0 & -0.556 & 0.604 \\
\hline $\mathrm{C} 1.4$ & 0.0 & 50.0 & -1.226 & 0.268 & 33.3 & 50.0 & -0.497 & 0.673 \\
\hline $\mathrm{C} 1.5$ & \multicolumn{8}{|c|}{ No statistical test possible } \\
\hline C1.6 & 37.5 & 50.0 & -0.454 & 0.731 & 62.5 & 50.0 & -1.651 & 0.133 \\
\hline $\mathrm{C} 1.7$ & 0.0 & 16.7 & -1.333 & 0.310 & 16.7 & 0.0 & -0.873 & 0.447 \\
\hline $\mathrm{C} 1.8$ & 25.0 & 25.0 & 0.000 & 1.000 & 12.5 & 25.0 & -0.131 & 0.905 \\
\hline C1.9 & 0.0 & 25.0 & -0.601 & 0.662 & 0.0 & 0.0 & 0.000 & 1.000 \\
\hline $\mathrm{C} 1.10$ & \multicolumn{8}{|c|}{ No statistical test possible } \\
\hline
\end{tabular}

For both the under-12 players and the under-16 players, the test result showed that there were no significant differences in the capacity for players to recall the serve and return of serve behaviour across the eight categories analysed. This may show that players of both genders at these age groups possess a comparable capacity for recalling serve and serve-return patterns, which may be due to a function of the highly variable responses within each group. 
Table 7.Summary statistics of the Mann-Whitney u tests: Difference in pattern recognition between the male under-12 and under-16 players and the female under-12 and under-16 players

\begin{tabular}{|c|c|c|c|c|c|c|c|c|}
\hline \multirow{3}{*}{ Category } & \multicolumn{4}{|c|}{ Boys } & \multicolumn{4}{|c|}{ Girls } \\
\hline & \multicolumn{2}{|c|}{ Median } & \multirow{2}{*}{$\mathbf{U}$} & \multirow{2}{*}{$\mathbf{p}$} & \multicolumn{2}{|c|}{ Median } & \multirow{2}{*}{$\mathbf{U}$} & \multirow{2}{*}{$\mathbf{P}$} \\
\hline & Under-12 & Under-16 & & & Under-12 & Under-16 & & \\
\hline C1.1 & 50.0 & 50.0 & -0.056 & 0.958 & 50.0 & 50.0 & -0.166 & 0.918 \\
\hline $\mathrm{C} 1.2$ & 41.7 & 16.7 & -0.745 & 0.492 & 0.0 & 16.7 & -0.589 & 0.613 \\
\hline $\mathrm{C} 1.3$ & 16.7 & 25.0 & -0.172 & 0.875 & 50.0 & 25.0 & -0.867 & 0.408 \\
\hline C1.4 & 0.0 & 33.3 & -1.142 & 0.298 & 50.0 & 50.0 & -0.362 & 0.779 \\
\hline C1.5 & \multicolumn{8}{|c|}{ No statistical test possible } \\
\hline C1.6 & 37.5 & 62.5 & -1.740 & 0.093 & 50.0 & 50.0 & -0.058 & 1.000 \\
\hline C1.7 & 0.0 & 16.7 & -1.503 & 0.220 & 16.7 & 0.0 & -0.735 & 0.529 \\
\hline $\mathrm{C} 1.8$ & 25.0 & 12.5 & -0.057 & 0.958 & 25.0 & 25.0 & -0.334 & 0.758 \\
\hline $\mathrm{C} 1.9$ & 0.0 & 0.0 & -0.223 & 0.898 & 25.0 & 0.0 & -0.451 & 0.689 \\
\hline C1.10 & \multicolumn{8}{|c|}{ No statistical test possible } \\
\hline
\end{tabular}

The post-match recall capabilities of junior high-performance tennis players with respect to in-game serve and serve-return performance were also examined. A comparison of the post-match questionnaire responses to actual match performance still revealed no gender or age group differences, particularly in the capacity of players to detect and document their own and their opponent's serve and serve-return patterns.

Research has reported that more experienced players have better recognition and performance recall compared to their less experienced counterparts [12, 26-31]. However, our results indicate that this heightened capacity may not be as developed in the under-16 teenage group. A range of median scores of $12.5 \%-62.5 \%$ for recall accuracy of players serve and serve-return (independent of score) has no direct comparison in the literature, since it has not been fully studied yet. However, past researchesdone on youth and sports suggest that early teenage athletes have underdeveloped encoding and retrieval systems, and that younger players (8- to 10 -years old) possess insufficient processing operations to drive proper game solutions [32-33]. Despite this important finding, this current research and its data have 
limitations that do not allow direct discussion whether a recall capacity of these players is poorer or better. Although the age groups were not that different based on the findings, the under-12 group may have performed better on that day of the tournament than the under-16 group. It is also possible that the under-12 group had easier matches, leading perhaps to fewer action instances to recall. The ability of an athlete to recall details correctly has implications for both declarative and procedural knowledge. Inaccurate recall of details will lead to inaccuracies to both knowledge bases [18] and less than optimal performance. A comparison of professional tennis players to elite collegiate players revealed that professional players displayed more consistent and higher order tactical processing and behaviour [34].

The results of this existing study suggest where junior players can improve, particularly on their attention to and memory during matches. However, no significant age or skill interaction in retrieving player position information was found among soccer players aged between 11 and 13 years of age, suggesting that athletes may start developing more accurate encoding and retrieval systems between the ages of 15 and 17 years. The results of the present study do not confirm or refute the data and suggestions of [30] as there was no novice control group. Henceforth, this is not a generalizable criterion to determine "good accuracy" or "poor accuracy".

The current sample of under-12 and under-16 age group players showed an inadequacy of necessary cognitive skills to accurately recall specific game information. For this reason, further research is needed to determine the pattern recall of this age group as well as adult professional players is needed. This is also related to further understanding the importance of recall in all age groups. In addition, a notational analysis of the details of these behaviours may be necessary to help develop their declarative knowledge in tennis and/or aid in the review of match performances rather than merely relying on memory recall post-match.

In our study, it is possible that the players were unpracticed in systematically recognizing and recalling, not only the actions of themselves but also of their opponents. Moreover, players may also be unfamiliar at responding in detail of these behaviours while under the duress of a competition loss. Accomplished tennis players were not always proficient in verbalizing or expressing what they thought they were doing [35]. Poor accuracy on recall of shot location might actually be inversely related to skill. For example, among golf players, experts display 
poorer episodic memory for the events during the match than less skilled players, arguably because their declarative memories are more proceduralised and less available to conscious recollection [36]. Further, a player can discern 'what to do' (declarative knowledge) in game situations without being able to explain or express the characteristics of that information when asked [37]. In other words, an elite level athlete's technical and tactical skills are often operationalized at an automatic/implicit level, and as such not easy to consciously declare it [38-39].

In this research, the under-12 and under-16 age group players answered the questionnaires. However, the player's responses were not clarified with further probing as a result of the constraints of collecting data during a national tennis tournament which is also considered as a limitation of this study. Alternatively, if time permitted the researchers to undertake in-depth interviews, a more comprehensive understanding of players' thinking could have been obtained. Unfortunately, such questionnaires cannot be administered during competition matches. Hence, future researchers could use this method in delving on the similar topic.

It is also worth noting that certain methodological or design issues may have contributed to the current results. Only players who had recently lost a match were sampled, which may have affected their motivation for recall. Information was collected after a series of games and could be subject to forgetting. The specificity, length and format (pen to paper) of the questionnaire given to athletes who are not used to filling out questionnaires and to accurately recall specific behaviour may have been too intrusive considering their typical post-match routine. Finally, the criteria that underpinned which game tactics and responses to be sampled may have been too conservative. The current study only considered situations where the 'same event' occurred $\geq 3$ times over the course of the match. In retrospect, this may have provided players with too few opportunities to recall accurately, particularly when contained to just one match and to develop meaningful associations between the score and serve/serve-return performance.

In summary, it would seem that the field of research in the area of pattern recognition has produced mixed results. The findings of the current study are a case in point. Nonetheless, it implies that the pattern recall capacity of male and female high-performance junior players, aged between 12 and 16, relating to serve and serve-return performance post-match is equally 
developed which is a result consistent with past researches. In a practical context, this finding can be understood to shape the manner in which coaches provide tactical instruction to and ask for game-related feedback from players of different ages.

\section{CONCLUSION AND RECOMMENDATIONS}

The results of the current study show that there were no gender or age differences in the post-match recall of the serve and serve-return location(s) among high-performance junior players. These players may have similarly developed declarative knowledge bases. The researchers suggest the use of more objective notational, game reviews or instructional tools, particularly for players within this age group.Junior players are then encouraged to improve and focus ontheir core cognitive processes that underlie performance in many different areas. These processes include memory, attention and other abilities that are critical in the game of tennis. This may be through the use of interactive multimedia software technology and self-organized learning environments.

The relative inaccuracy of junior players pattern recall suggests that an on-court coach who could chart and discuss strategic episodes may positively impact on themental performance of junior players. This study has provided a method from which potential research can apply alternative interview techniques or operational definitions of serve and serve-return patterns to improve our understanding of situational probability information in tennis. The inclusion of professional tennis players, as a potential gold standard would also enhance our understanding of the role and meaningfulness of recall in coach instruction and player development.

\section{ACKNOWLEDGEMENTS}

This study was undertaken with the help of Tennis Australia and the support of The University of Western Australia.

\section{REFERENCES}

[1] MacMahon C, McPherson S L.Knowledge base as a mechanism for perceptual-cognitive tasks: Skill is in the details! International Journal of Sport Psychology, 2009, 40(4):565-579 [2] French K E, NevettM E. The development of expertise in youth sport. In J. L. Starkes,\& F. 
Allard (Eds.),Cognitiveissues in motor expert. Amsterdam: Elsevier, 1993, pp. 255-270

[3] Anderson J. R. Language, memory, and thought. New Jersey: Erlbaum, 1976

[4] AndersonJ R, RederL M, Lebiere C. Working memory: Activation limitations on retrieval.Cognitive Psychology, 1996, 30(3):221-256

[5] Allard F, Deakin J, Parker S, Rodgers W. Declarative knowledge in skilled motor performance: Byproduct or constituent?In J. L. Starkes,\& F. Allard (Eds.), Advances in Psychology.Amsterdam: Elsevier, 1993, pp. 95-107

[6] Baddeley A D. Working memory: The interface between memory and cognition.Journal of Cognitive Neuroscience, 1992, 4(3):281-288

[7] Williams A M, Davids K. Declarative knowledge in sport: A by-product of experience or a characteristic of expertise? Journal of Sport and Exercise Psychology, 1995, 17(3):259-275

[8] Ericsson KA, Kintsch W. Long-term working memory.Psychological Review, 1995, 102(2):211-245

[9] Farrow D, Abernethy B. Can anticipatory skills be learned through implicit video-based perceptual training? Journal of Sports Sciences, 2002, 20(6):471-485

[10] Farrow D, Chivers P, Hardingham C, Sachse S. The effect of video-based perceptual training on the tennis return of serve.International Journal of Sport Psychology, $1998,29(3): 231-242$

[11] McPherson S L, Kernodle M W. Mapping two new points on the tennis expertise continuum: Tactical skills of adult advanced beginners and entry-level professionals during competition.Journal of Sports Sciences,2007, 25(8):945-959

[12] Farrow D, McMurtrie D, Handke D, Reid M. Expert perception of situational probability information in a time-stressed interactive task. Journal of Sport and Exercise Psychology, 2010, 32:S77

[13] McPhersonS L. Expert-novice differences in performance skills and problem representations of youth and adults during tennis competition.Research Quarterly for Exercise and Sport, 1999, 70(3):233-251

[14] McPherson S L. Tactical differences in problem representations and solutions in collegiate varsity and beginner women tennis players.Research Quarterly for Exercise and Sport, 1999, 70(4):369-384 
[15] McPhersonS L. Expert-novice differences in planning strategies during collegiate singles tennis competition.Journal of Sport and Exercise Psychology, 2000, 22(1):39-62

[16] McPhersonS L. Analyzing tactical skills via verbal reports.Research Quarterly for Exercise and Sport, 2003, 74(1):A99-A100

[17] McPherson S L., Kernodle M W.Problem representations of male professionals and novices during tennis competition.Research Quarterly for Exercise and Sport,2002, 73(1):A50-A50

[18] McPherson S L., KernodleM W. Tactics the neglected attribute of champions: Problem representations and performance skills in tennis. In J. L. Starkes, \& K. A. Ericsson (Eds.),Recent advances in research on sport expertise. Illinois: Human Kinetics, 2003, pp. $137-167$

[19] Fery Y, Crognier L. On the tactical significance of game situations in anticipating ball trajectories in tennis. Research Quarterly for Exercise and Sport, 2001, 72(2):143-149

[20] Oudejans R R D, Michaels C F, Bakker F C. The effects of baseball experience on movement initiation in catching fly balls.Journal of Sports Sciences, 1997,15(6):587-595

[21] Williams A M, Ward P, Knowles J M, Smeeton N J. Anticipation skill in a real-world task: Measurement, training, and transfer in tennis.Journal of Experimental Psychology: Applied,2002, 8(4):259-270

[22] Ripoll H.Uncertainty and visual strategies in table tennis.Perceptual and Motor Skills, $1989,68(2): 507-512$

[23] O'Donoghue P. The effect of scoreline on elite tennis strategy: A cluster analysis. Journal of sports Sciences, 2003, 21(4):284-285

[24] Scully D, O'Donoghue P G. The effect of score line on tennis strategy in Grand Slam men's singles.Journal of Sports Sciences, 1999, 17(1):64-65

[25] Hodges N J., Huys R, Starkes J L. Methodological review and evaluation of research in expert performance in sport. In G. Tenenbaum, R. C. Eklund,\& R. N. Singer (Eds.), Handbook of sport psychology. New Jersey: John Wiley and Sons,2007, pp. 161-183

[26] AbernethyB, Baker J, Cote J. Transfer of pattern recall skills may contribute to the development of sport expertise.Applied Cognitive Psychology, 2005, 19(6):705-718

[27] BakerJ,Côté J. Shifting training requirement during athlete development: Deliberate 
practice, deliberate play and other sport involvement in the acquisition of sport expertise. In D. Hackfort,\& G. Tenenbaum (Eds.), Essential processes for attaining peak performance. Ontario: Meyer and Meyer Sport Ltd., 2006, pp. 92-109

[28] Farrow D.Reading the play in team sports: Yes it is trainable!Sports Coach, 2004,27(3):12-13

[29] Smeeton N J, Ward P, WilliamsA M. Do pattern recognition skills transfer across sports? A preliminary analysis.Journal of Sports Sciences, 2003, 22(2):205-213

[30] Ward P, Williams A M. Perceptual and cognitive skill development in soccer: The multidimensional nature of expert performance.Journal of Sport and Exercise Psychology, 2003, 25(1):93-111

[31] Williams A. M., Davids K., Williams J. G.Visual perception and action in sport. London: E and FN Spon, 1999

[32] French K E, Nevett M E, Spurgeon J H, Graham K C, Rink J E, McPherson S L. Knowledge representation and problem solution in expert and novice youth baseball players.Research Quarterly for Exercise and Sport, 1996, 67(4):386-395

[33] Nevett M E, French K E. The development of sport-specific planning, rehearsal, and updating of plans during defensive youth baseball game performance.Research Quarterly for Exercise and Sport, 1997, 68(3):203-214

[34] Nielsen T M, McPhersonS L. Response selection and execution skills of professionals and novices during singles tennis competition.Perceptual and Motor Skills, 2001,93(2):541-555

[35] Braden V., Bruns B.Tennis 2000: Strokes, strategy, and psychology for a lifetime. New York: Little, Brown and Company, 1998.

[36] BeilockS L, Wierenga S A, CarrT H. Expertise, attention, and memory in sensorimotor skill execution: Impact of novel task constraints on dual-task performance and episodic memory.Quarterly Journal of Experimental Psychology: Section A, 2002, 55(4):1211-1240

[37] Magill R A.Knowledge is more than we can talk about: Implicit learning in motor skill acquisition.Research Quarterly for Exercise and Sport, 1998, 69(2):104-110

[38] Davids K, Myers C. The role of tacit knowledge in human skill performance. Journal of Human Movement Studies, 1990, 19(6):273-288 
[39] Myers C, David K. Tacit skill and performance at work.Applied Psychology, 1993,42(2):117-137

\section{How to cite this article:}

Hizan, H., Whipp, P. and Reid, M. Post-match recall of serve and serve-return patterns in high-performance junior male and female tennis players. J. Fundam. Appl. Sci., 2017, 9(6S), 469-489. 